\title{
UI LOKASI HIPOSENTER MIKRO-EARTHQUAKE (MEQ) DENGAN METODE INVERSI SIMULATED ANNEALING PADA LAPANGAN PANAS BUMI "XX"
}

\author{
Gian Ricardo Halim, Widya Utama, Mariyanto Mariyanto \\ Departemen Teknik Geofisika, Fakultas Teknik Sipil, Perencanaan dan Kebumian, Institut Teknologi Sepuluh \\ Nopember, Surabaya \\ e-mail: gianricardohalim@gmail.com
}

\begin{abstract}
Abstrak. Energi sangat berpengaruh untuk kegiatan-kegiatan manusia. Sumber energi sendiri didapatkan melalui proses eksplorasi sumber daya alam. Kini sudah banyak macam kegiatan eksplorasi yaitu eksplorasi mineral, eksplorasi minyak dan gas bumi serta yang baru-baru ini sedang digalakkan yaitu eksplorasi panas bumi atau biasa disebut dengan geothermal. Eksplorasi panas bumi adalah terobosan untuk sumber energi terbarukan. Untuk memenuhi kegiatan eksplorasi, maka dari itu perlu dilakukan survei geofisika untuk menggambarkan kondisi bawah permukaan agar dapat memaksimalkan kegiatan eksplorasi dan pemanfaatan sumber energi. Untuk menunjang kegiatan di area panas bumi digunakan metode seismik pasif yaitu pencatatan aktivitas gempa mikro. Data gempa mikro merupakan hasil perekaman gelombang seismik natural dengan frekuensi yang rendah dan memiliki nilai magnitudo $(\leq 3$ SR). Gempa dalam skala yang kecil ini biasanya disebabkan oleh adanya aktivitas simulasi hidraulik, produksi/injeksi, pengeboran atau kegiatan lain yang berhubungan dengan eksplorasi reservoir sekitar area panas bumi. Penelitian ini bertujuan untuk melakukan uji lokasi titik hiposenter dengan metode inversi Simulated Annealing. Hasil dari metode inversi ini akan dilihat hasilnya dengan penelitian yang ada sebelumnya. Parameter untuk menentukan baik tidaknya suatu metode akan dilihat dari nilai misfit atau RMS. Metode inversi Simulated Annealing ternyata lebih baik dibandingkan metode-metode yang sering digunakan untuk menentukan titik hiposenter karena hasilnya tidak terjebak pada minimum lokal dan memiliki nilai misfit yang lebih kecil. Input dari metode inversi ini adalah lokasi stasiun, model kecepatan 1 dimensi, travel time, dan inisiasi hiposenter awal. Untuk hasil yang didapatkan dari metode ini pada dasarnya adalah lokasi yang lebih presisi secara perhitungan dilihat dari nilai misfit yang didapat.

Kata Kunci: eksplorasi, geothermal; misfit; Simulated Annealing
\end{abstract}

Abstract. Energy is very influence for human activities. The energy source itself is obtained through the process of exploration of natural resources. Now there are many kinds of exploration activities, namely mineral exploration, oil and gas exploration and recently being promoted, namely geothermal exploration or commonly referred to as geothermal. Geothermal exploration is a breakthrough for renewable energy sources. To fulfill exploration activities, a geophysical survey is needed to describe the subsurface conditions in order to maximize exploration activities and the utilization of energy sources. To support activities in the geothermal area, a passive seismic method is used to record micro-earthquake activity. Micro-earthquake data is the result of recording natural seismic waves with low frequency and has a magnitude value ( $\leq 3 S R$ ). These small-scale earthquakes are usually caused by hydraulic simulations, production /injection, drilling or other activities related to reservoir exploration around geothermal areas. This study aims to test the hypocenter point with the Simulated Annealing inversion method. The results of this inversion method will be seen the results with existing research. The parameter to determine whether or not a method will be seen from the value of misfit or RMS. The Simulated Annealing inversion method turns out to be better than the methods used before because the result is not trapped at the local minimum and has a smaller misfit value. Inputs from this inversion method are station location, 1dimensional speed models, travel time, and initial hypocenter initiation. For the results obtained from this method is basically a location that is more precise in calculations calculated from the value of the misfit obtained.

Keywords: eksploration; geothermal; misfit; Simulated Annealing

\section{PENDAHULUAN}

Banyak metode inversi yang dapat diterapkan pada data gempa mikro terutama untuk menentukan lokasi hiposenter gempa mikro itu sendiri. Semua metode inversi memiliki kelebihan dan kekurangan, tergantung pada kebutuhan yang ingin dicapai. Dengan adanya penelitian ini penulis mengusung metode inversi Simulated Annealing 
yang dianggap lebih cocok untuk diterapkan pada data gempa mikro lapangan panas bumi " $X X$ ". Adapun parameter untuk menentukan baik atau tidaknya kedua metode tersebut adalah misfit atau RMS dari proses inversi masing-masing metode.

\section{TINJAUAN PUSTAKA DATA}

Data yang digunakan pada penelitian ini adalah data riil yang diambil pada lapangan " $X X$ " dengan format (*.msd). Data yang digunakan akan disortir berdasarkan kenampakan event dalam masa perekaman data. Setelah dilakukan sortir data, selanjutnya adalah converting data dari (*.msd) menjadi (*.mseed). Setelah di convert, maka data akan di picking pada program Seisgram $2 \mathrm{~K}$ dan dilakukan rekapitulasi hasil picking pada Ms. Excel. Selanjutnya, proses yang cukup memegang peranan yang besar yaitu pembuatan model kecepatan bawah permukaan. Model ini nanti nya akan menjadi input data pada proses Inversi, baik metode Geiger, maupun Simulated Annealing. Setelah Model dibuat, lalu masuk ke bagian perhitungan inversi. Pada proses ini input data yang dibutuhkan akan dijelaskan pada alur penelitian pada subbab skema kerja. Output dari proses inversi ini adalah lokasi hiposenter terupdate setelah perhitungan. Hasil dari proses inversi akan direkapitulasi di Ms. Excel dan dievaluasi nilai RMS nya setelah di lakukan Inversi Simulated Annealing.

\section{SISTEM PANAS BUMI}

Area panas bumi sering dibagi kedalam beberapa klasifikasi. Ada tipe dominan air atau dominan uap, rendah atau tingginya temperatur panas bumi, proses sedimentasi atau keberadaan vulkanik dan lain sebagainya. Dalam sistem panas bumi pun biasa dibagi dalam beberapa kedaan kesetimbangan reservoar panas bumi, tipe fluida, temperatur reservoar, host rock, dan sumber panas. Berdasarkan tipe fluida sebuah reservoar panas bumi dapat dibagi menjadi sebagian dominasi cair (water dominated) dan dominasi uap (vapour dominated). Temperatur reservoar menjadi faktor yang sangat penting dalam penentuan pontensi sumber energi dan host rock sebagai peninjau komposisi air dan gas dari reservoar. Sedangkan untuk sirkulasi fluida dan aliran panas dalam reservoar sangat penting untuk memperhatikan kesetimbangan reservoarnya (Natania dkk., 2019). Dinamika kesetimbangan didefinisikan dengan aktivitas air di area reservoar secara terus menerus yang memasuki reservoar. Fluida yang telah dipanaskan pada reservoar akan dikeluarkan ke permukaan dan panas akan diteruskan melalui sistem dengan proses konveksi dari aliran fluida.

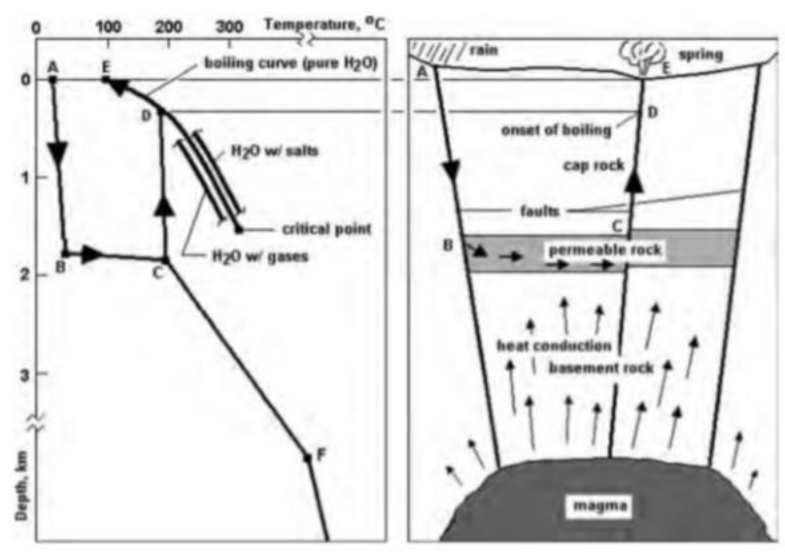

Gambar 2.1. Skema sistem panas bumi

\section{METODE SEISMIK}

Gelombang merupakan rambatan energi yang mampu memindahkan partikel dari suatu tempat sesuai dengan arah rambatannya. Gelombang seismik membutuhkan medium untuk merambat, dan medium yang dirambati adalah lapisan dibawah permukaan bumi. Gelombang seismik akan muncul disebabkan oleh adanya aktivitas deformasi dari struktur di dalam bumi yang bersifat elastis yaitu tarikan ataupun regangan. Proses tersebut biasanya berupa aktivitas vulkanik, ledakan buatan maupun gempa bumi tektonik (Indrastuti dkk., 2019). Gelombang seismik akan menjalarkan rambatannya ke segala arah di seluruh bagian bumi maka dari itu gelombang seismik biasa disebut gelombang elastik. Disebut gelombang elastik karena osilasi partikel-partikel medium terjadi akibat dari interaksi antara gradien stress melawan gaya-gaya elastik. Ketika gelombang menjalar ke segala arah maka gelombang itu akan diterima dipermukaan sebagai sinyal yang dicatat oleh seismograf (Kandilarov dkk., 2015).

\section{MICRO-EARTHQUAKE}

Metode microearthquake (MEQ) memang tidak sepopuler metode geofisika lainnya seperti geolistrik maupun seismik, tetapi MEQ merupakan salah satu metode geofisika yang cukup baik karena memanfaatkan sumber gelombang seismik natural dan berfrekuensi rendah (Nugraha dkk., 2013). 
Konsep pengukuran dalam metode MEQ hampir sama dengan metode seismik, yaitu menangkap gelombang getar yang berasal dari sumber getar atau sumber gempa hanya saja melihat dari sumber yang ditangkap, MEQ merupakan metode pasif. MEQ pada penggunaannya di area panas bumi akan merekam gempa-gempa atau gerakan-gerakan kecil ( $\leq 3 \mathrm{SR}$ ) serta mencari frekuensi gempa yang dominan dan biasanya terbentuk akibat induksi yang disebabkan oleh aktivitas simulasi hidraulik, produksi/ injeksi, pengeboran dan kegiatan lainnya pada reservoar panas bumi. Secara sederhana metode ini akan merekam sinyal yang akan dibaca sebagi event-event seismik (gempa mikro) yang ada di suatu tempat. Sama dengan cara kerja jaringan seismograf di dunia untuk mempelajari gempa, walaupun magnitude yg terekam lebih kecil dengan resolusi yg lebih baik tentunya (Idat dan Harmoko, 2016).

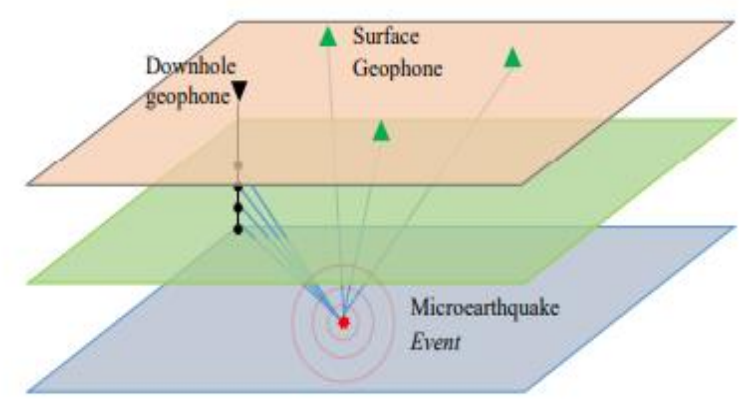

Gambar 2.2. Konsep microearthquake

Terjadinya gempa mikro pada lapangan geothermal dapat disebabkan oleh beberapa faktor. Faktor tersebut diantaranya:

1). Bergesernya zona lemah akibat adanya aktivitas air yang diinjeksikan dan meningkatnya tekanan dalam batuan.

2). Adanya kontak antara air dingin dengan batuan beku panas (heat source) sehingga dapat direspon sebagai sumber.

3). Hilangnya tekanan pori akibat pori yang kosong karena ada aktivitas produksi (pengangkatan fluida ke permukaan) (Isroi dan Singarimbun, 2015).

\section{UJI LOKASI GEMPA MIKRO}

Dalam menentukan posisi hiposenter gempa memerlukan perhitungan secara komputasi dari travel time antara sumber dengan stasiun melalui koreksi lokasi (stasiun). Dalam penentuan hiposenter, diperlukan model kecepatan yang mirip dengan struktur aslinya. Meminimalisir root mean square (RMS) residual adalah solusi dalam pemodelan struktur bumi. Selisih antara waktu observasi dengan waktu datang kalkulasi (Ri) disebut RMS residual. Dugaan hiposenter awal, linearisasi persamaan, dan perhitungan solusi akan dijadikan input dalam Penentuan RMS.

$$
R M S=\sqrt{\frac{\sum_{i=1}^{N} R_{i}^{2}}{N-1}}
$$

Proses ini akan berlangsung terus menerus sampai perubahan dugaan hiposenter semakin kecil dan mendekati aslinya, Solusi yang dihasilkan tersebut dapat digunakan sebagai dugaan hiposenter terupdate (Isroi dan Singarimbun, 2015).

\section{PENENTUAN RAY TRACE METODE SHOOTING}

Perhitungan menggunakan metode ray tracing metode shooting digunakan Untuk menentukan waktu tempuh gelombang $P$ dan $S$ yang merambat dari sumber gempa ke stasiun penerima dengan bantuan model kecepatan seismik 1-D atau disebut model kecepatan bawah permukaan. Sudut datang dan transmisi pada setiap batas lapisan akan ditentukan sesuai dengan hukum Snellius, diformulasikan oleh persamaan berikut:

$$
\frac{V_{1}}{V_{2}}=\frac{\sin \emptyset_{1}}{\sin \emptyset_{2}}
$$

lintasan gelombang berujung tepat pada koordinat stasiun penerima bila permasalahan dirumuskan dengan mencari sudut atau arah tembak yang tepat (Ry dan Nugraha, 2015a).

\section{SIMULATED ANNEALING}

Metode guided random search atau pencarian acak terarah yang cukup populer adalah metode simulated annealing (SA) (Grandis, 2009). Metode ini pada penjelasannya diterapkan dari sebuah analogi pengkristalan oleh suatu substansi. Dalam temperatur tinggi suatu substansi padat akan mencair kemudian proses pendinginan akan berlangsung secara perlahan-lahan dan menyebabkan terbentuknya kristal dalam substansi tersebut. Pembentukan kristal ini akan berasosiasi dengan energi sistem yang minimum (Ry dan Nugraha, 2015b).

Dalam metode simulated annealing ini, interval harga minimum dan maksimum parameter 
model ruang harus didefinisikan terlebih dahulu dengan menentukan secara "a priori", dalam penelitian kali ini parameter modelnya adalah hiposenter gempa inisial. Pemilihan harga interval nilai minimum dan maksimum masing-masing parameter model ditentukan secara acak sebagai bilangan sembarang. Caranya adalah mengambil bilangan acak $\mathrm{R}$ dengan probabilitas uniform antar 0 dan 1 yang dipetakan menjadi harga parameter model.

Untuk mendefinisikan konfigurasi sistem dan fungsi objektif (misfit) sebagai energi, Proses pembentukan kristal (annealing) dalam termodinamika diadopsi untuk penyelesaian masalah inversi dengan menggunakan parameter model. Temperatur merupakan faktor pengontrol dalam proses ini. Probabilitas perturbasi model dinyatakan oleh persamaan berikut:

$$
P(\Delta E)=\exp \left(-\frac{\Delta E}{T}\right)
$$

dimana $\Delta E$ didefinisikan sebagai perubahan fungsi objektif atau perubahan misfit akibat perturbasi model yang dilakukan terus menerus. Jika $\Delta \mathrm{E} \geq 0$, maka penentuannya ditentukan secara probabilistik menggunakan bilangan acak $\mathrm{R}$ yang terdistribusi uniform pada interval $[0,1]$. Jika $\Delta \mathrm{E}<0$, maka perubahan model diterima. Namun, jika nilai $R<$ $P(\Delta E)$ maka perubahan diterima, sebaliknya jika $R \geq P(\Delta E)$ perubahan ditolak dan kembali kemodel sebelumnya lalu melanjutkan proses perhitungan kembali (iterasi). semua perturbasi model diterima diawal karena proses iterasi dimulai dengan temperatur cukup tinggi. Pada saat temperatur turun secara perlahan, perturbasi model yang diterima akan mengecil dengan adanya syarat jika $\Delta \mathrm{E} \geq 0$ (Ry dan Nugraha, 2015b).

\section{METODOLOGI}

\section{Penelitian Terdahulu}

Penelitian mengenai Micro-Earthquake pada lapangan panas bumi "XX" pernah dilakukan oleh Naomi Nadya Angelia Siregar dengan judul "Penentuan Lokasi Hiposenter Gempa Bumi Mikro Menggunakan Metode Geiger dengan Arrival Times P-wave dan S-wave berdasarkan S-Transform" pada tahun 2019. Sama halnya dengan penelitian yang pernah dilakukan disini hal yang diangkat adalah metode yang lebih unggul dibandingkan sebelumnya (Angelia, 2019).

\section{Skema Kerja}

Adapun skema kerja pada penilitian ini dibagi menjadi 2, yaitu gambar (8) berupa skema utama pengerjaan dari penelitian yang dilakukan dan gambar (9) berupa skema metode simulated Annealing untuk mengetahui bagaimana alur jalannya proses inversi.

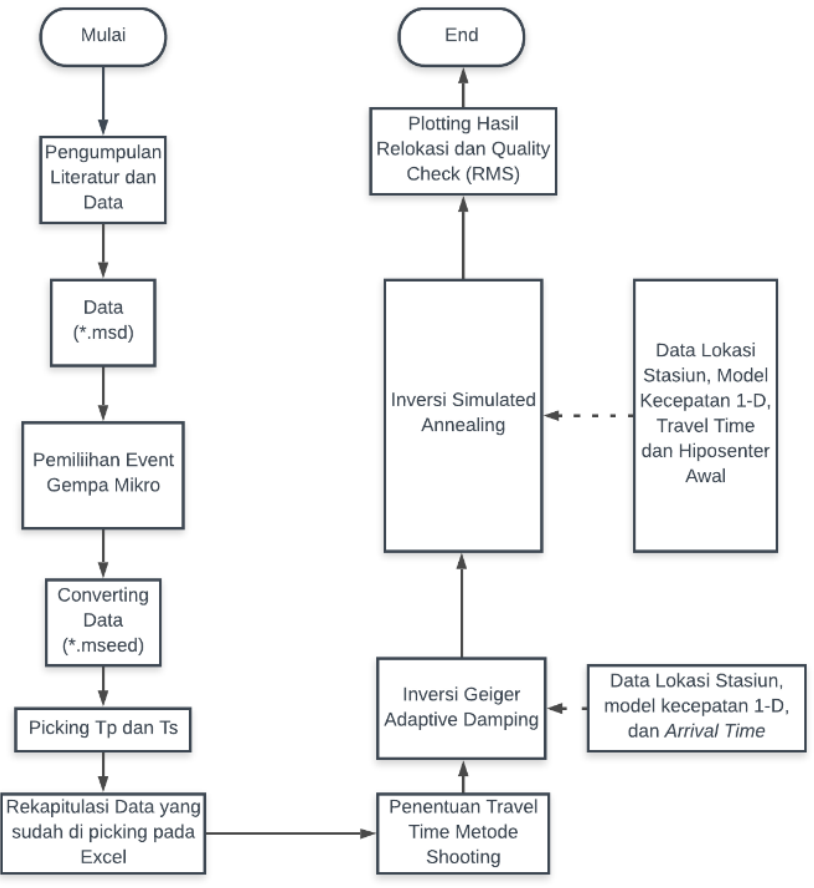

Gambar 8. Skema Kerja Output Akhir Penelitian.

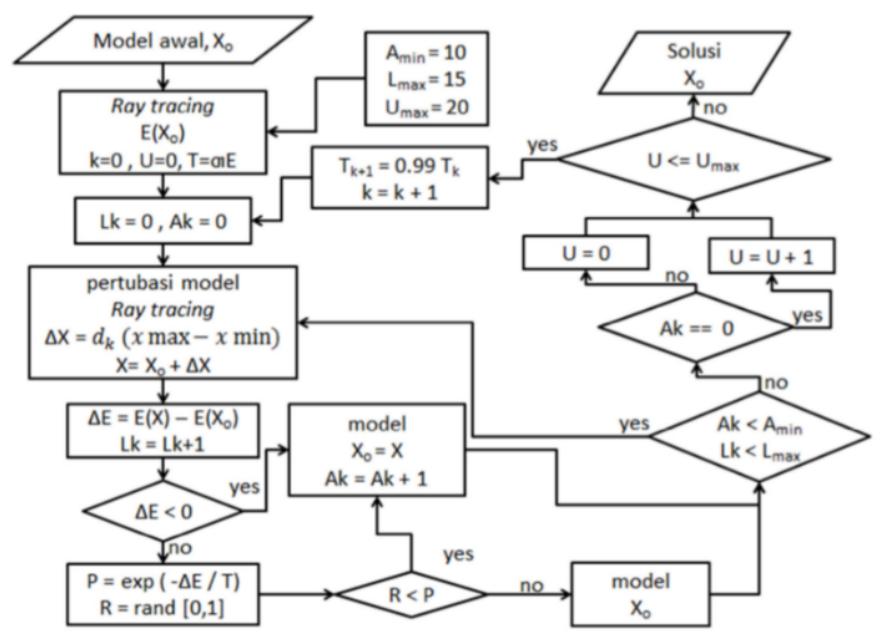

Gambar 9. Alur Kerja Metode Inversi Simulated Annealing

\section{Perangkat}

Perangkat lunak yang digunakan pada penelitian tugas akhir ini adalah MATLAB 2017a (64 bit), VELEST, dan GAD yang dijalankan pada perangkat keras laptop dengan spesifikasi: 


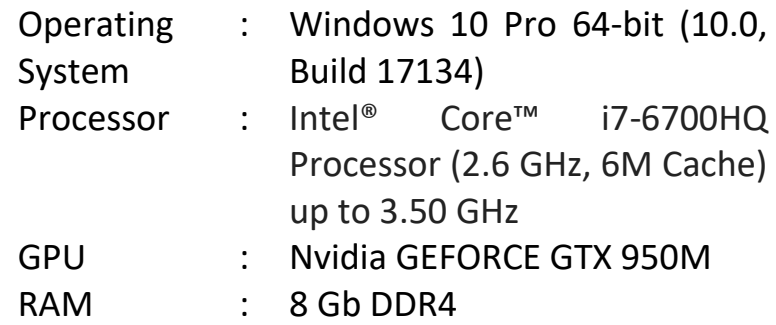

\section{HASIL DAN PEMBAHASAN}

Dari Penelitian yang dilakukan dapat dilihat metode inversi Simulated Annealing dapat menjawab permasalahan yang ada pada penelitian terdahulu. Untuk hasil yang didapatkan dari pengolahan berupa 363 titik lokasi hiposenter dan nilai error. Untuk hasil visualisasi titik hiposenter, dilakukan plotting secara 3-Dimensi dan menambahkan ilustrasi topografi disekitar lokasi dengan data DEM dan peta RBI.

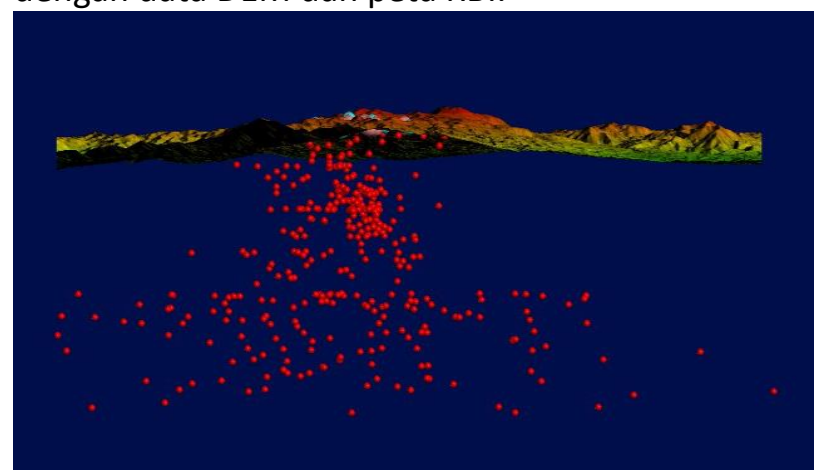

Gambar 10. Penampang 3-Dimensi West-East

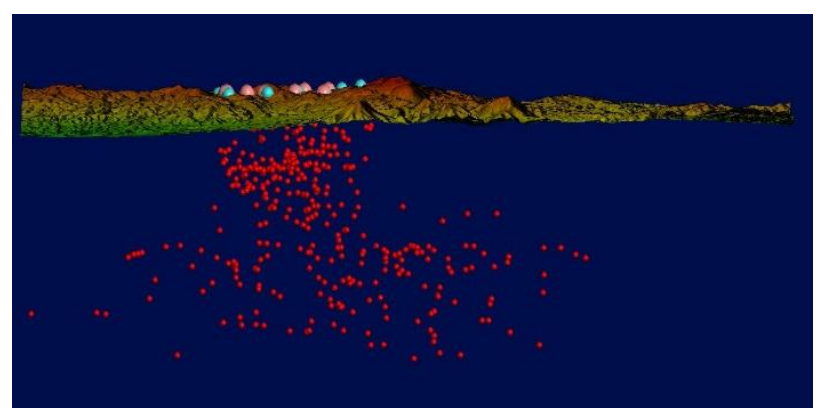

Gambar 11. Penampang 3-Dimensi South-North

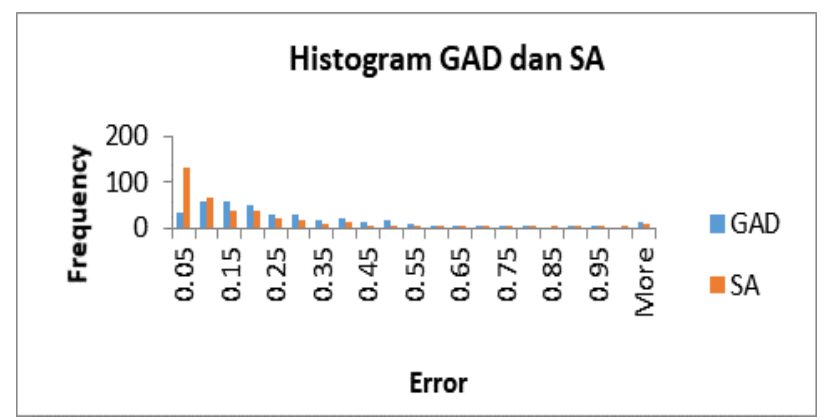

Gambar 12. Histogram Error dari Metode Geiger dan Simulated Annealing
Dapat dilihat dari histogram, nilai error yang dihasilkan antara 2 metode melihatkan bahwa metode Simulated Annealing terbukti lebih mengelompokkan hasil pengolahan dengan nilai error yang berada pada range 0 - 0.05 sebanyak 131 data. Sedangkan pada metode Geiger Adaptive Damping dengan range yang sama hanya menghasilkan 32 data. Ini mendukung bahwa penurunan nilai average error yang telah dibahas sebelumnya dibuktikan oleh hasil nilai error metode Simulated Annealing yang dihasilkan terletak pada range $0-0.05$ bertambah cukup banyak.

Metode Geiger adaptive Damping memberikan solusi yang terjebak pada minimum lokal, sedangkan solusi dari Metode Simulated Annealing memberikan solusi yang lebih tersebar pada zona kedalaman yang merata. Secara kuantitatif metode yang diangkat mampu memberikan error jauh lebih kecil hingga $37.165 \%$ lebih kecil dibandingkan Metode Geiger Adaptive Damping. Penyebab dari adanya solusi yang terjebak pada minimum lokal adalah adanya faktor Damping pada skema perhitungan Metode Geoger Adaptive Damping. Faktor Damping tersebut tidak digunakan dalam Metode Simulated Annealing yang mengakibatkan solusi memiliki semesta yang luas untuk setiap iterasinya

\section{PENUTUP \\ Simpulan}

Berdasarkan hasil yang telah dibahas sebelumnya, maka dapat diambil beberapa kesimpulan, yaitu:

1. Metode Simulated Annealing teruji memberikan solusi yang tidak terjebak pada minimum lokal dan menghilangkan efek damping dari penelitian sebelumnya;

2. Metode Simulated Annealing memerlukan data input meliputi model kecepatan, lokasi stasiun, travel time, dan inisial hiposenter. Output dari pengolahan menghasilkan 363 event gempa bumi mikro yang jumlahnya sesuai dengan jumlah data input inisial hiposenter. Melihat dari hasil persebaran titik Hiposenter, mayoritas data terletak di area Heat-Source hingga Reservoir pada model konseptual pengukuran metode Magnetotelurik sebagai data sekunder yang digunakan. Hal ini mengindikasikan adanya aktifitas fluida disekitar well produksi lapangan panas bumi; 
3. Hasil perhitungan hiposenter dengan metode Simulated Annealing menurunkan nilai error sebesar $37.165 \%$ dibandingkan dengan metode Geiger yang digunakan sebagai data input. Secara histogram jumlah nilai error terbanyak berada pada range $0-0.05$ sebanyak 131 data dari 363 data

\section{Saran}

Adapun saran yang diperlukan untuk meningkatkan kualitas dan pengembangan penelitian lebih baik,

1. Penggunaan model kecepatan yang sesuai dengan lapangan untuk mendapatkan hasil hiposenter yang lebih akurat;

2. Menganalisis data seismogram secara periodik untuk memonitoring aktivitas seismik pada sekitar lapangan panas bumi;

3. Pengolahan data lebih lanjut dengan tujuan mengetahui pergerakan fluida pada aktivitas eksploitasi.

\section{Ucapan Terima Kasih}

Terima kasih saya ucapkan untuk Dr. Widya Utama, DEA dan Mariyanto sebagai pembimbing dalam pengerjaan penilitian serta penulisan paper ini. Dan terima kasih kepada Orang tua penulis, rekan rekan Teknik Geofisika 2016 serta kepada seluruh elemen departemen Teknik Geofisika dalam mendukung pengerjaan penelitian.

\section{DAFTAR PUSTAKA}

Angelia, N. (2019), Penentuan Lokasi Hiposenter Gempa Bumi Mikro menggunakan Metode Geiger dengan Arrival Times P-wave dan S-wave berdasarkan S-Transform Institut Teknologi Sepuluh Nopember,.

Grandis, H. (2009), "Pengantar pemodelan inversi geofisika", Himpunan Ahli Geofisika Indonesia (HAGI),

Idat, C.F. dan Harmoko, U. (2016), "RELOKASI HIPOSENTER GEMPA MIKRO DENGAN METODE SED DAN JHD SEBAGAI ANALISIS RESERVOAR AREA PANAS BUMI-X", YOUNGSTER PHYSICS JOURNAL, Vol.5, No.3, hal. 97-104.

Indrastuti, N., Nugraha, A.D., McCausland, W.A., Hendrasto, M., Gunawan, H., Kusnandar, R., Kasbani dan Kristianto (2019), "3-D Seismic Tomographic Study of Sinabung Volcano, Northern Sumatra, Indonesia, during the Inter-
Eruptive Period October 2010-July 2013", Journal of Volcanology and Geothermal Research, Vol.382, hal. 197-209. http://doi.org/10.1016/j.jvolgeores.2019.03.00 1.

Isroi, A.R. dan Singarimbun, A. (2015), Relokasi Hiposenter Gempa Mikro Menggunakan Metode SED (Single Event Determination) di Area Geothermal Kamojang, hal. 4.

Kandilarov, A., Mjelde, R., Flueh, E. dan Pedersen, R.B. (2015), "Vp/Vs-Ratios and Anisotropy on the Northern Jan Mayen Ridge, North Atlantic, Determined from Ocean Bottom Seismic Data", Polar Science, Vol.9, No.3, hal. 293-310. http://doi.org/10.1016/j.polar.2015.06.001.

Natania, K.A., Sahara, D.P., Nugraha, A.D. dan Ramadhan, I. (2019), "The Physical Mechanisms of Geothermal Reservoir During Hydraulic Injection Through Microearthquake Tomography", Journal of Physics: Conference Series, Vol.1204, hal. 012081. http://doi.org/10.1088/17426596/1204/1/012081.

Nugraha, A.D., Widiyantoro, S., Ramdhan, M., Mujihardi, B., Widarto, D.S., Hasanah, M.U., Akbar, A.F., Juanda, A.A. dan Tommi (2013), "Analysis of Micro-seismic Events Through Waveform Identification and Hypocenter Determination Around a Geothermal Field in West Java", dalam Proceedings of the 11th SEGJ International Symposium, Yokohama, Japan, 18-21 November 2013, SEG Global Meeting Abstracts, Society of Exploration Geophysicists of Japan, hal. 418421. http://doi.org/10.1190/segj112013-106.

Ry, R.V. dan Nugraha, A.D. (2015a), "Improve earthquake hypocenter using adaptive simulated annealing inversion in regional tectonic, volcano tectonic, and geothermal observation", AIP Conference Proceedings, Vol.1658, No.April 2015. http://doi.org/10.1063/1.4915012.

Ry, R.V. dan Nugraha, A.D. (2015b), "Improve earthquake hypocenter using adaptive simulated annealing inversion in regional tectonic, volcano tectonic, and geothermal observation", AIP Conference Proceedings, Vol.1658, No.1, hal. 030004. http://doi.org/10.1063/1.4915012. 